\title{
Sensorless control of PMSM with fuzzy model reference adaptive system
}

\author{
Larbi M'hamed, Adjir Roufaida, Ait Amer Meziane Nawa \\ L2GEGI-Labotatory, University Ibn-Khaldoun of Tiaret, Algeria
}

\begin{tabular}{|c|c|}
\hline Article Info & ABSTRACT \\
\hline Article history: & \multirow{9}{*}{$\begin{array}{l}\text { To improve the performance of permanent-magnet synchronous motor } \\
\text { (PMSM) drives powered by the voltage inverter with PWM control, a } \\
\text { sensorless control scheme based on a Model Reference Adaptive System } \\
\text { (MRAS) a fuzzy logic controller (FLC) based in with fuzzy supervisor } \\
\text { structure. The major drawbacks of the conventional MRAS, namely } \\
\text { chattering phenomena, high-order harmonics andexternal noise, are } \\
\text { discussed. These drawbacks affect the estimated speed accuracy of the MRAS } \\
\text { and reduce the control reliability of the system. To eliminate these } \\
\text { drawbacks, an FLC is designed and integrated into the MRAS to adjust the } \\
\text { observer gain to reduce the chattering in closed loop speed and closed loop } \\
\text { current/torque. Comparative simulations using the proposed Fuzzy-MRAS } \\
\text { and the conventional MRAS are performed to validate the effectiveness of the } \\
\text { proposed FLC structure. Performance simulations of the overall proposed } \\
\text { Fuzzy-MRAS based sensorless control scheme are performed to verify the } \\
\text { robustness and control reliability of the system. The results show that the } \\
\text { proposed Fuzzy MRAS has satisfactory performances with reduction of total } \\
\text { harmonic distortion generated in the phase currents. }\end{array}$} \\
\hline Received Mar 1, 2019 & \\
\hline & \\
\hline Accepted Jul 8, 2019 & \\
\hline Keywords: & \\
\hline$P M S M$ & \\
\hline Pulse Width Modulation PWM & \\
\hline & \\
\hline Supervisor Control & \\
\hline
\end{tabular}

Copyright (C) 2019 Institute of Advanced Engineering and Science. All rights reserved.

\section{Corresponding Author:}

Larbi M'hamed, L2GEGI-Labotatory, University Ibn-Khaldoun of Tiaret, 14000, Algeria.

Email: larbi_mh@yahoo.fr

\section{INTRODUCTION}

In numerous applications today, Permanent Magnet Synchronous Motor (PMSM) is the preferred AC drive compared to the others because of its special features, for instance, high power density, high torque to current ratio and high efficiency. Hence, PMSM has been widely used in various fields and applications such as manufacturing equipment, production machines, transportations, etc [1]. As an important application of PMSM, the motion control requires not only the accurate knowledge of rotor position for field orientation but also the information of rotor speed for closed-loop control; thus, position transducers such as optical encoders and resolvers are needed to be installed on the shaft [2-3]. However, these sensors are expensive and very sensitive to environmental constraints such as vibration and temperature [4]. In order to overcome these problems, instead of using position sensors, a sensorless control method has been developed for control of the motor. The basic principle of sensorless control is to deduce the rotor speed and position using various information and means, including direct calculation, parameter identification, condition estimation, indirect measuring and so on. The stator currents and voltages are generally used to calculate the information of speed and rotor position [5-6].

The Model Reference Adaptive System makes use of the redundancy of two machine models of different structures that estimate the same state variable (rotor speed) of different set of input variables. The estimator that does not involve the quantity to be estimated is chosen as the reference model, and the other 
estimator may be regarded as the adjustable model. The error between the estimated quantities obtained by the two models is proportional to the angular displacement between the two estimated flux vectors [6-7].

However, the conventional MRAS for PMSM sensorless control suffers chattering problem [8-9]. The presence of external disturbances and parameters variations in the motor limits the dynamic performances of the traditional vector control method, when conventional PI regulators are used.

So the aim of the present study is to develop a simple control strategy, which exploits the advantages of the vector control strategy of the PMSM and overcomes the limitations of PI regulator in the conventional MRAS obsever and in current loops. So, the combination of classical PI regulator and adaptive fuzzy supervisor makes it possible to increase the precision of the mathematical algorithm in the classical controllers with flexibility and simplicity of fuzzy linguistic formalism [14].

An adaptive fuzzy supervisor controller, have been proposed for the PMSM sensorless control in closed loop estimate speed and closed loop current/torque.

\section{MODELING OF THE SYSTEM}

The synchronous permanents magnets machine can be elaborated by carrying out a modeling within the meaning of Park. The machine model in the turning dysphasic reference (d-q) is written [8-9]:

$$
\frac{d}{d t}\left[\begin{array}{c}
I_{s d} \\
I_{s q} \\
\omega
\end{array}\right]=\left[\begin{array}{c}
-\frac{R_{s}}{L_{s d}} I_{s d}+\frac{L_{s q}}{L_{s d}} \omega I_{s q} \\
-\frac{L_{s d}}{L_{s q}} \omega I_{s d}-\frac{R_{s}}{L_{s q}} I_{s q}-\frac{\phi_{f}}{L_{s q}} \omega \\
\frac{P^{2}}{J}\left(\left(L_{s d}-L_{s q}\right) I_{s d} I_{s q}+\phi_{f} I_{s q}\right)-\frac{F}{J} \omega
\end{array}\right]+\left[\begin{array}{cc}
\frac{1}{L_{s d}} & 0 \\
0 & \frac{1}{L_{s q}} \\
0 & 0
\end{array}\right]\left[\begin{array}{c}
V_{s d} \\
V_{s q}
\end{array}\right]
$$

The electromagnetic torque is given by:

$$
C_{e m}=\frac{2}{3} P\left[\left(L_{s d}-L_{s q}\right) I_{s d} I_{s q}+\phi_{f} I_{s q}\right]
$$

\section{MRAS SENSORLESS SPEED CONTROL}

Figure 1 shows the MRAS based speed estimation scheme. It uses the outputs of two models: one independent of rotor speed (Reference Model) and the other dependent on rotor speed (Adjustable Model), to form an error signal. A PI controller is used in the adaptation mechanism for convergence in the system [11-12-13].

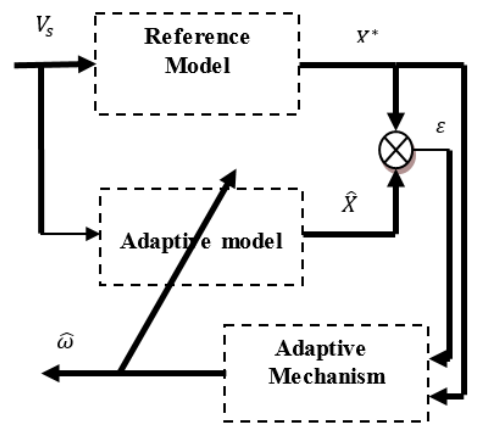

Figure 1. Structure MRAS for the estimate speed

The state space d-q axis stator currents of PMSM designed as reference model is given by:

$$
\left[\begin{array}{c}
\dot{I_{s d}} \\
\dot{I_{s q}}
\end{array}\right]=\left[\begin{array}{cc}
-\frac{1}{\tau_{d}} & \omega \frac{L_{s q}}{L_{s d}} \\
-\omega \frac{L_{s d}}{L_{s q}} & -\frac{1}{\tau_{q}}
\end{array}\right]\left[\begin{array}{l}
I_{s d} \\
I_{s q}
\end{array}\right]+\left[\begin{array}{cc}
-\frac{1}{L_{s d}} & 0 \\
0 & -\frac{1}{L_{s q}}
\end{array}\right]\left[\begin{array}{c}
V_{s d} \\
V_{s q}
\end{array}\right]+\left[\begin{array}{c}
0 \\
-\omega \frac{\phi_{f}}{L_{s q}}
\end{array}\right]
$$


The state space d-q axis stator currents of PMSM designed as adjustable model is given by:

$$
\left[\begin{array}{l}
\hat{i}_{s d} \\
\hat{\dot{I}}_{s q}
\end{array}\right]=\left[\begin{array}{cc}
-\frac{1}{\tau_{d}} & \omega \frac{L_{s q}}{L_{s d}} \\
-\omega \frac{L_{s d}}{L_{s q}} & -\frac{1}{\tau_{q}}
\end{array}\right]\left[\begin{array}{l}
\hat{I}_{s d} \\
\hat{I}_{s q}
\end{array}\right]+\left[\begin{array}{cc}
-\frac{1}{L_{s d}} & 0 \\
0 & -\frac{1}{L_{s q}}
\end{array}\right]\left[\begin{array}{l}
V_{s d} \\
V_{s q}
\end{array}\right]+\left[\begin{array}{c}
0 \\
-\widehat{\omega} \frac{\phi_{f}}{L_{s q}}
\end{array}\right]
$$

After developing adjustable and reference models, the adaptation mechanism will be built for MRAS method.

The adaptation mechanism is designed in a way to generate the value of estimated speed used so to minimize the error between the estimated and reference $\mathrm{d}-\mathrm{q}$ axis stator currents. The error between the estimated and reference $d-q$ axis stator currents are defined as:

$$
\left\{\begin{array}{l}
\varepsilon_{d}=I_{s d}-\hat{I}_{s d} \\
\varepsilon_{q}=I_{s q}-\hat{I}_{s q}
\end{array}\right.
$$

The state currents error component is:

$$
\left[\begin{array}{c}
\dot{\varepsilon d} \\
\dot{\varepsilon q}
\end{array}\right]=\left[\begin{array}{cc}
-\frac{1}{\tau_{d}} & \widehat{\omega} \frac{L_{s q}}{L_{s d}} \\
-\widehat{\omega} \frac{L_{s d}}{L_{s q}} & -\frac{1}{\tau_{q}}
\end{array}\right]\left[\begin{array}{l}
\varepsilon d \\
\varepsilon q
\end{array}\right]+\left[\begin{array}{c}
\frac{L_{s q}}{L_{s d}} \hat{I}_{s q} \\
-\frac{L_{s d}}{L_{s q}} I_{s d}-\frac{\phi_{f}}{L_{s q}}
\end{array}\right](\omega-\widehat{\omega})
$$

The state error model of the PMSM in the d-q synchronous reference frame is given as flow:

$$
[\dot{\varepsilon}]=[\mathrm{A}][\varepsilon]+[\mathrm{W}]
$$

Where $[\varepsilon]$ is the error state vector.

$[W]$ is the output vector of the feedback block.

The system is asymptotically hyper stable when the counter-reaction block reacts to the Popov inequality [11-12-13]:

$$
\int_{0}^{t_{1}}[\varepsilon]^{\mathrm{T}}[\mathrm{W}] \mathrm{dt} \geq-\gamma^{2} \text { in which } \mathrm{t}_{1} \geq 0
$$

Finally, we can conclude that the observed rotor speed satisfiers the following adaptation laws:

$$
\begin{aligned}
& \omega=A_{1}+\frac{A_{2}}{S} \\
& \mathrm{~A}_{1}=\mathrm{k}_{\mathrm{p} \widehat{\omega}}\left[\frac{\mathrm{L}_{\mathrm{sq}}}{\mathrm{L}_{\mathrm{sd}}} \hat{\mathrm{I}}_{\mathrm{sq}} \varepsilon_{\mathrm{d}}-\left(\frac{\mathrm{L}_{\mathrm{sd}}}{\mathrm{L}_{\mathrm{sq}}} \mathrm{I}_{\mathrm{sd}}+\frac{\phi_{\mathrm{f}}}{\mathrm{L}_{\mathrm{sq}}}\right) \varepsilon_{\mathrm{q}}\right] \\
& A_{2}=k_{i \widehat{\omega}}\left[\frac{L_{s q}}{L_{s d}} \hat{I}_{s q} \varepsilon_{d}-\left(\frac{L_{s d}}{L_{s q}} I_{s d}+\frac{\phi_{f}}{L_{s q}}\right) \varepsilon_{q}\right]
\end{aligned}
$$

Where $k_{p \widehat{\omega}}$ and $\mathrm{k}_{\mathrm{i} \widehat{\omega}}$ are the PI speed observer controller

The rotor estimated speed is generated from the adaptation mechanism using the error between the estimated and reference currents obtained by the model as follows:

$$
\widehat{\omega}=\left(k_{p \widehat{\omega}}+\frac{k_{i \widehat{\omega}}}{s}\right)\left[\frac{L_{s q}}{L_{s d}} \hat{I}_{s q} \varepsilon_{d}-\left(\frac{L_{s d}}{L_{s q}} I_{s d}+\frac{\phi_{f}}{L_{s q}}\right) \varepsilon_{q}\right]
$$

Finally, the estimated rotor position is obtained by integrating the estimated rotor speed.

$$
\hat{\theta}=\frac{1}{S} \widehat{\omega}
$$

\section{PMSM FUZZY SUPERVISOR CONTROL}

This system is composed of two parts: a block PI type correction and the block for the fuzzy supervisor control [14]. The control system block diagram suggested is presented in Figure 2. 


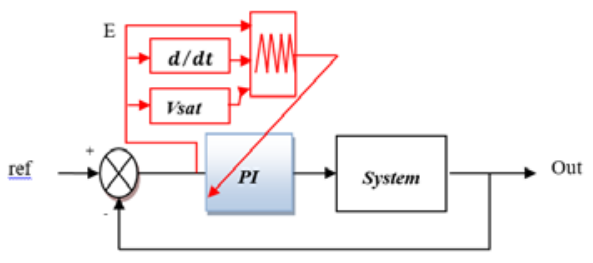

Figure 2. Block diagram of the proposed control system.

\subsection{Classical PI correction}

The PI regulator is used to produce a control response that is a function of the error magnitude.The Proportional term $(\mathrm{P})$ of the regulator is formed by multiplying the error signal by a $\mathrm{P}$ gain .As the error signal becomes larger, the $\mathrm{P}$ term of the regulator becomes larger to provide more correction. In short, $\mathrm{P}$ is a magnify function.

The Integral term (I) of the regulator is used to eliminate small steady errors. The (I) term calculates a continuous running total of the error signal. Therefore, a small steady state error accumulates into a large error value over time. This accumulated error signal is multiplied by an I gain factor and becomes the (I) output term of the PI regulator.

\subsection{Fuzzy Logic control}

Fuzzy logic is able to use human reasons not in terms of discrete symbols and numbers, but in terms of fuzzy sets. These terms are quite flexible with respect to the definition and values. The Basic configuration of a Fuzzy Logic Controller (FLC) consists of the following components [14-15]:

a. Fuzzifier,

b. Fuzzyrule base,

c. Inference engine

d. Defuzzifier

The Fuzzifier changes the input (crisp signals) into fuzzy values. The fuzzy rule base consists of basic data and linguistic rules. The engine is the brain of a fuzzy controller which ability to simulate the human decision based on finally, the second transformation converts values into the real values.

A fuzzy controller is a special fuzzy system that can be used as a controller component in a closed loop system. The integration of a fuzzy system into a closed loop is shown. Special emphasis is put onto the transfer behavior of fuzzy controllers, which are analyzed using different configurations of standard Membership functions [14-15]

The combination of classical control and the fuzzy supervisor control are based on the speed error and its variation, the system performances respectively. We use the first advantage in transient state and the second advantage in the steady state. The proposition bases of fuzzy supervisor rules to generate the weights to be applied to each regulator gains $K_{P}, K_{i}$. The used heuristic laws are:

Increase $K_{p}$ if the system responses far from the reference to increase the convergence speed and decrease $K_{i}$ if the system response is near from the reference to anticipate the overshoot.

This strategy of improving the control law in transitory state helps us to obtain better responses than using only the PI regulator alone [14-15].

Performance such as response time, overshoot at startup, overshoot for Load application, the Load rejection time and the chattering reducing are the essentials elements of this strategy.

The inputs of the Fuzzy supervisor PI controller are the error (e), the error change (de/dt) and the saturation $\left(V_{s a t}=\right.$ Isat -Iqref), The Fis used in this study is a suguno type. The chosen membership function for the input variables has triangular shapes as shown in Figure 3. 

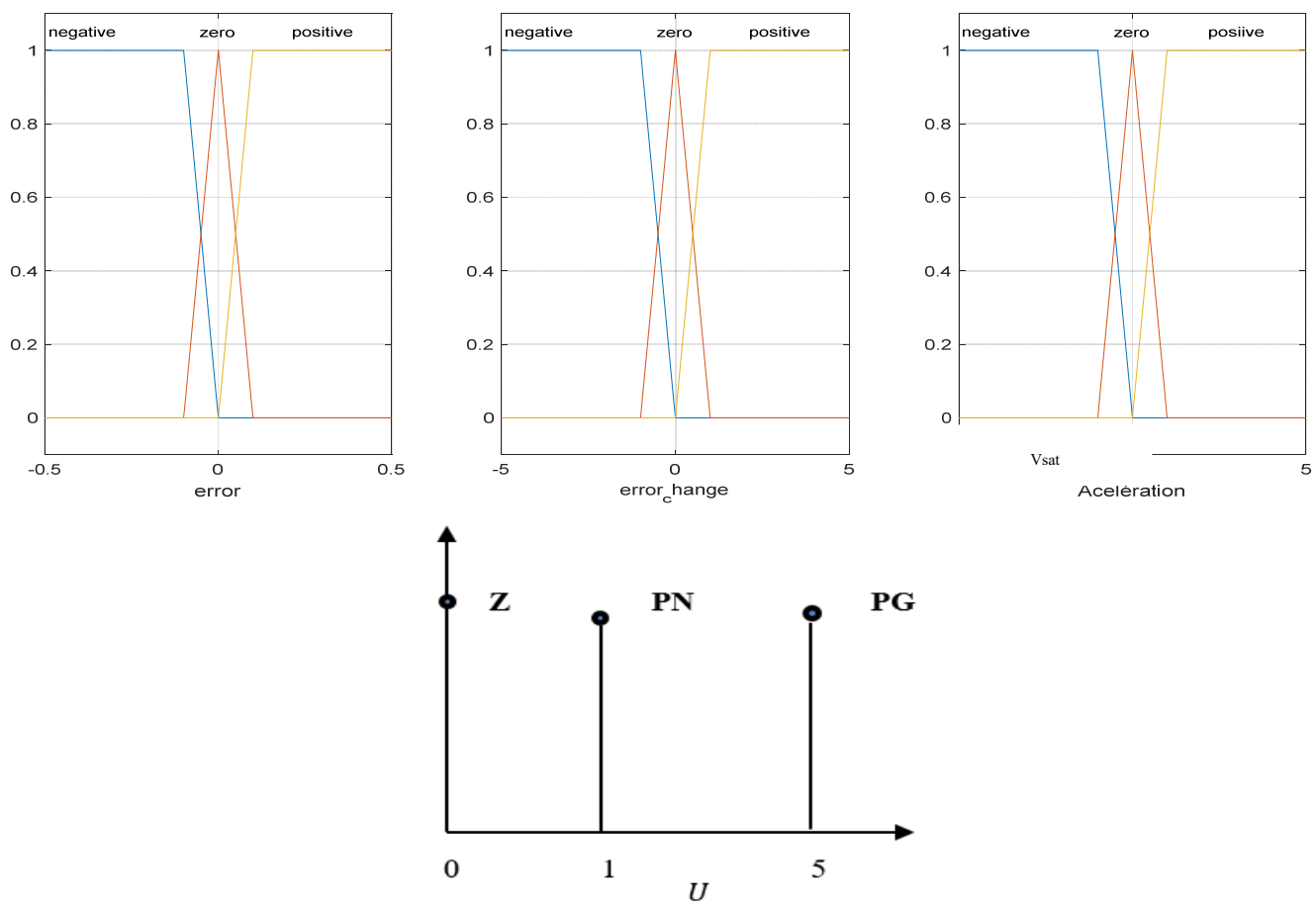

Figure 3. Input \& output membership function.

The rule base expressed by linguistic terms is shown in Table 1. Note that the distribution of rules in table is symmetric. After "défuzzification", the robustness analysis is quantified by the function $u=f$ (error, $d$-error, $\left.V \_s a t\right)$ which corresponds to a surface presented in Figure 4.

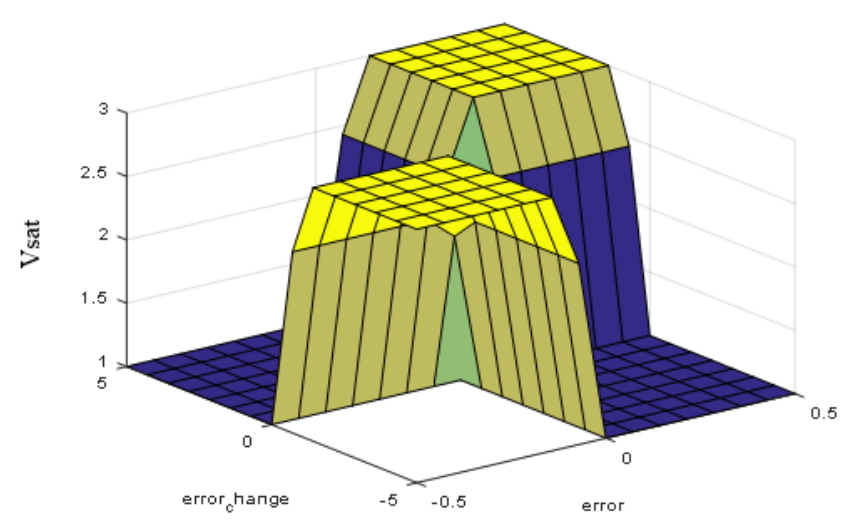

\begin{tabular}{cccc}
\multicolumn{4}{c}{ Table 1. Fuzzy Rules Used } \\
\hline$E_{r}$ & $d E_{r}$ & $V_{\text {sat }}$ & $U$ \\
\hline $\mathrm{N}$ & $/$ & $\mathrm{N}$ & $\mathrm{Z}$ \\
$\mathrm{N}$ & $/$ & $\mathrm{P}$ & $\mathrm{PG}$ \\
$\mathrm{P}$ & $/$ & $\mathrm{N}$ & $\mathrm{PG}$ \\
$\mathrm{P}$ & $/$ & $\mathrm{P}$ & $\mathrm{Z}$ \\
$\mathrm{Z}$ & $/$ & $/$ & $\mathrm{PN}$ \\
$/$ & $/$ & $\mathrm{Z}$ & $\mathrm{PN}$ \\
$/$ & $\mathrm{Z}$ & $/$ & $\mathrm{PN}$ \\
$\mathrm{N}$ & $\mathrm{N}$ & $\mathrm{Z}$ & $\mathrm{PG}$ \\
$\mathrm{P}$ & $\mathrm{P}$ & $\mathrm{Z}$ & $\mathrm{PG}$ \\
\hline
\end{tabular}

Figure 4. Fuzzy function (u) 


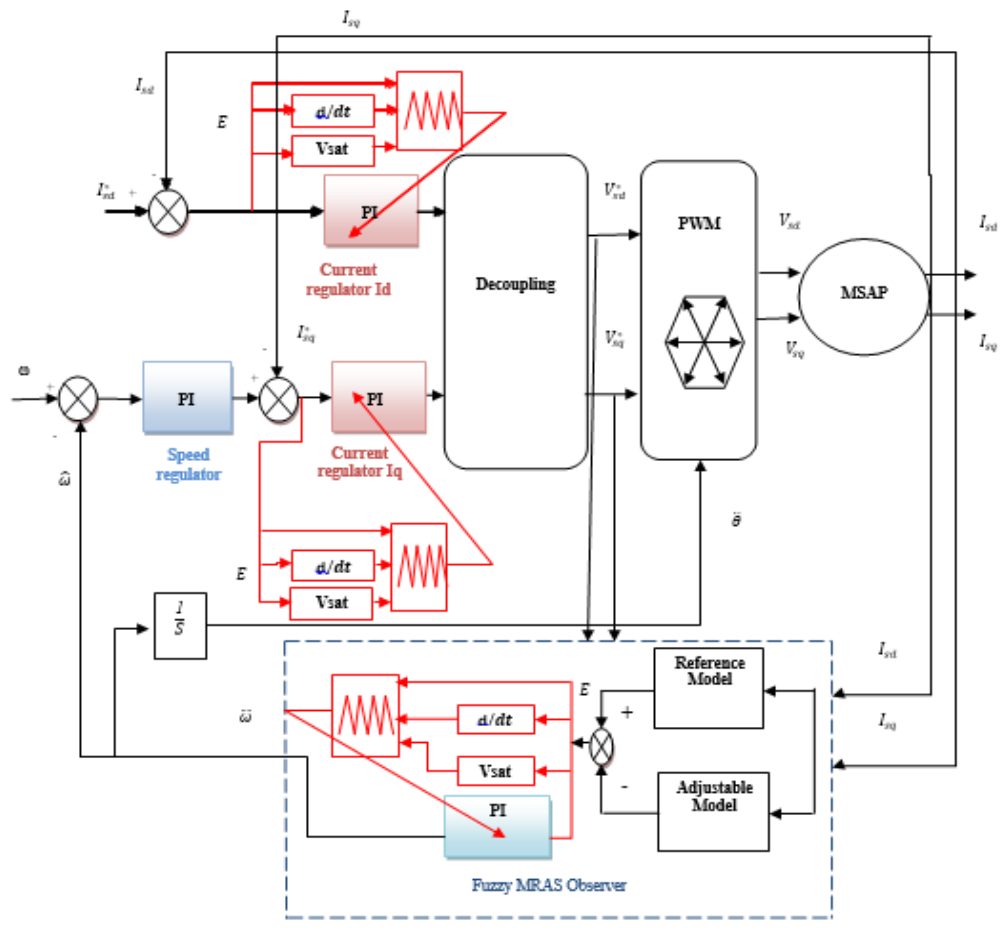

Figure 5. Block diagram of sensorless vector control of PMSM

\section{SIMULATION RESULTS AND DISCUSSIONS}

To demonstrate the performance of the proposed control scheme (see Figure 5), a set of simulations is carried out on a PMSM model by using SIMULINK/MATLAB. The parameters of the tested PMSM are given in Table 2. In this section, the speed setting is treated with adaptive fuzzy controller associated with Model Reference Adaptive System powered by the voltage inverter with PWM control. The speed reference trajectory is given by the following benchmark: $(0,+100,-100,0) \mathrm{rad} / \mathrm{s}$.

Table 2. Parameters of the motor

\begin{tabular}{lll}
\hline Components & Values & Units \\
\hline $\mathrm{C}_{\mathrm{n}}$ & 5 & $\mathrm{Nm}$ \\
$\Omega_{\mathrm{n}}$ & 1000 & $\mathrm{tr} / \mathrm{min}$ \\
$\mathrm{R}_{\mathrm{s}}$ & 1.67 & $\Omega$ \\
$\mathrm{L}_{\mathrm{s}}$ & 1.45 & $\mathrm{mH}$ \\
$\mathrm{P}$ & 3 &.--- \\
$\Phi_{f}$ & 0.17 & $\mathrm{~Wb}$ \\
$\mathrm{~J}$ & $3.10^{-4}$ & $\mathrm{Kg} \cdot \mathrm{m}^{2}$ \\
$\mathrm{~F}$ & 0.013 & $\mathrm{Nms} / \mathrm{rad}$ \\
\hline
\end{tabular}

Figure 6 and (Zoom of Startup and Load application) illustrate the simulation results by the model reference adaptive system (MRAS) with fuzzy suppervisor has superiority and gives the best performance and robustness relative to the Model Reference Adaptive System of sensorless vector control in terms of low speed behavior, speed reversion and load rejection as shown in Table 3, compensate considerably the disturbances caused by the load variations and minimize the torque ripples (current) developed by the motor (see Figure 7,8 and 9).

Table 3. Summary of proposed control simulation performance

\begin{tabular}{lllllll}
\hline Controller & $\mathrm{D}_{\mathrm{d}}(\%)$ & $\mathrm{T}_{\mathrm{r}}(\mathrm{s})$ & $\mathrm{T}_{\mathrm{m}}(\mathrm{s})$ & $\mathrm{E}_{\mathrm{s}}(\%)$ & $\mathrm{D}_{\mathrm{p}}(\%)$ & $\mathrm{T}_{\mathrm{p}}(\mathrm{s})$ \\
\hline MRAS & 1.258 & 0.04 & 0.04 & 0 & 13 & 0.017 \\
Fuzzy-MRAS & 0.8 & 0.04 & 0.04 & 0 & 4.8 & 0.013 \\
\hline
\end{tabular}


$\mathrm{D}_{\mathrm{d}}(\%) \quad$ The overshoot at startup

$\mathrm{D}_{\mathrm{p}}(\%) \quad$ The overshoot for load application

$\mathrm{T}_{\mathrm{r}}(\mathrm{s}) \quad$ The response time

$\mathrm{T}_{\mathrm{m}}(\mathrm{s}) \quad$ The rise time

$\mathrm{E}_{\mathrm{s}}(\%) \quad$ The static error

$\mathrm{T}_{\mathrm{p}}(\mathrm{s}) \quad$ The load rejection time

$\mathrm{V}_{\text {sd }}, \mathrm{V}_{\mathrm{sq}} \quad$ Stator winding $\mathrm{d}$, q axis voltage respectively

$\mathrm{I}_{\mathrm{sd}}, \mathrm{I}_{\mathrm{sq}} \quad$ Stator winding d, q axis current respectively

$\mathrm{I}_{\mathrm{sd}} * \mathrm{I}_{\mathrm{sq}} * \quad$ Reference stator winding d, q axis current respectively

$\Omega \quad$ The electric rotor speed

$\Omega^{*} \quad$ Reference rotor speed

$\widehat{\omega} \quad$ Estimated rotor speed

$\theta \quad$ Rotor position

$\Phi_{f} \quad$ Permanent Magnet Flux

$R_{S} \quad$ Stator phase resistance

$\mathrm{L}_{\mathrm{sd}}, \mathrm{L}_{\mathrm{sq}} \quad$ The stator inductances of the axis $\mathrm{d}, \mathrm{q}$

$\mathrm{J} \quad$ Inertia of turning parts

F Viscous friction coefficient

$\mathrm{P} \quad$ Poles pairs number

$\mathrm{C}_{\mathrm{r}} \quad$ Load torque

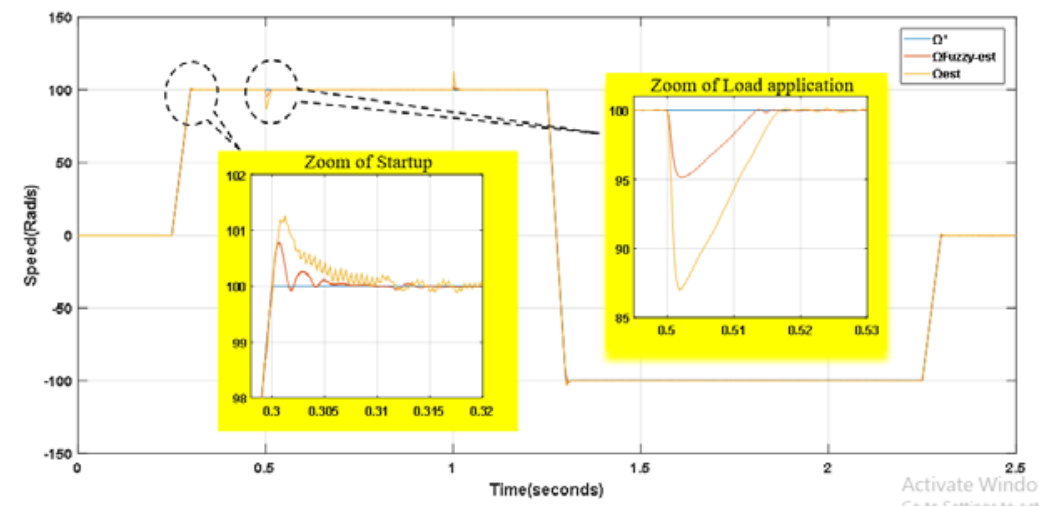

Figure 6. The rotational speed (real, estimated, reference) in the vector control based on MRAS
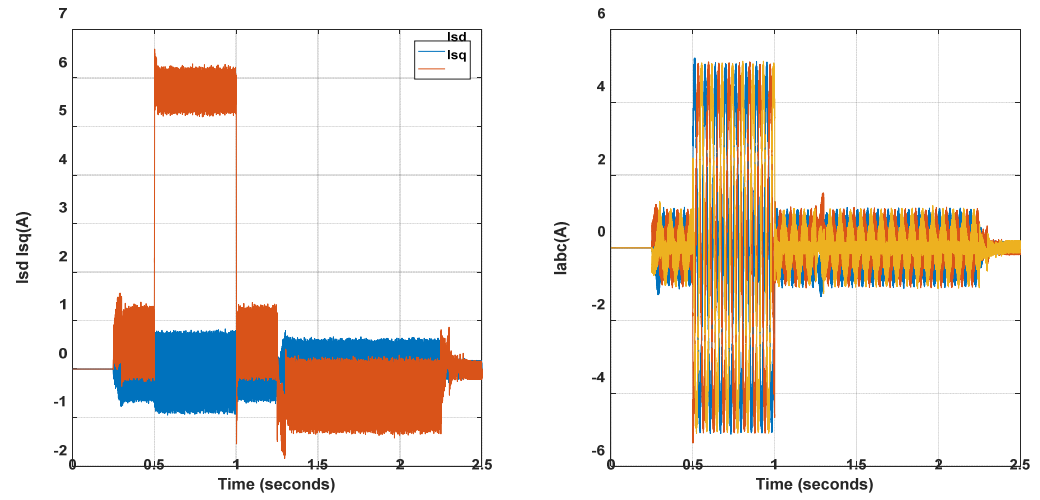

Figure 7: Simulation results: measured $I_{s q}$, measured $I_{s d}$, measured phase stator current (Vector control based classical control). 

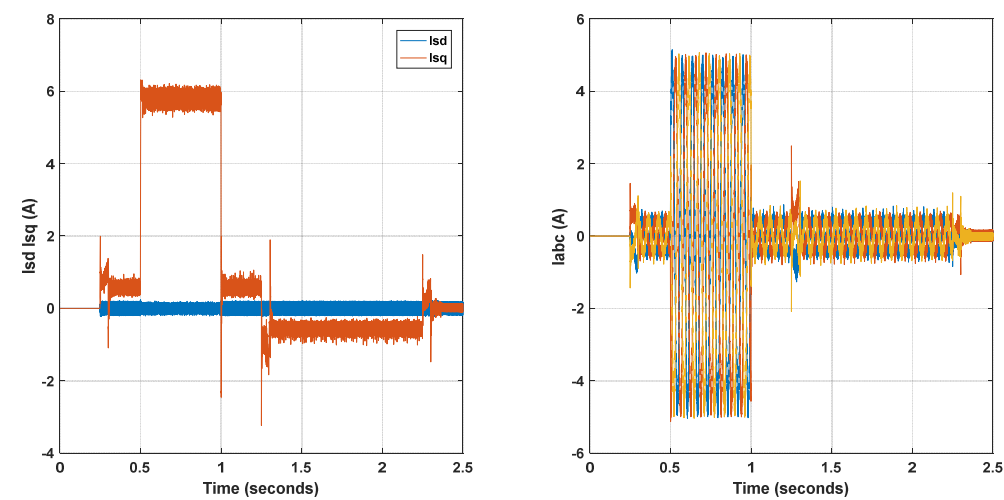

Figure 8. Simulation results: measured $I_{s q}$, measured $I_{s d}$, measured phase stator current (Vector control based adaptive fuzzy control)
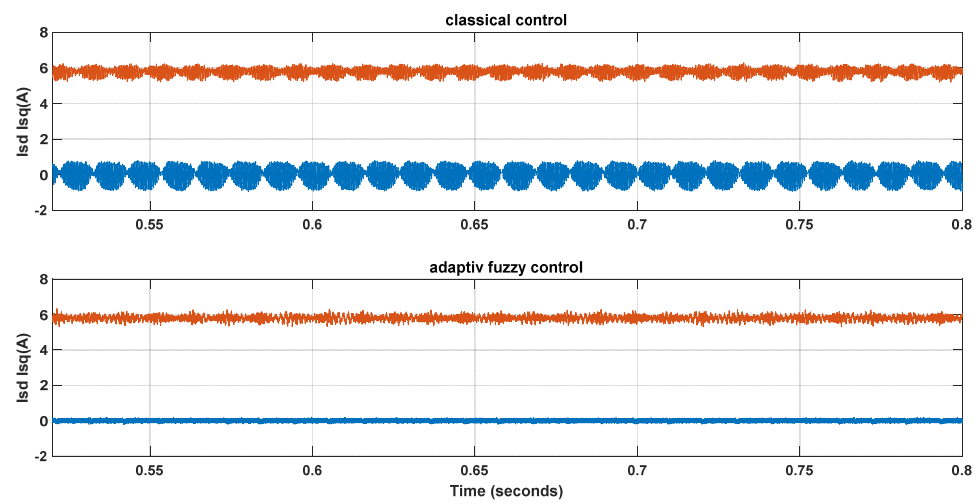

Figure 9. Simulation results: zoom of measured $I_{s q}$ and measured $I_{s d}$

\section{CONCLUSION}

A robust control sensorless of a permanent magnet synchronous motor is presented. The simulation results obtained in this work confirm its feasibility and validate excellent dynamic performance. The results show a good estimation under different operating conditions and low sensitivity to external disturbances they allowed us to get rid of especially mechanical speed sensor or position, which is expensive and fragile. Concluded against the Model Reference Adaptive System is simple to implement, don't take into account the measurement noise or the environment. It not require a long calculation time, and has a good dynamic response speed and good disturbance rejection, it show a response time and efficient robustness. According to the simulation results the model reference adaptive system (MRAS) with fuzzy suppervisor has superiority and gives the best performance and robustness relative to the Model Reference Adaptive System of sensorless vector control in terms of low speed behavior, speed reversion and load rejection with reduction of total harmonic distortion generated in the phase currents.

\section{REFERENCES}

[1] A. Asri, A. Dahman, A.Malek Saidina, S. Iqbal, M. Abdul Razak, "A new speed sensorless field oriented controller for PMSM based on MRAS and PSO," J. Electrical Systems, vol. 12(3), pp. 565-573, 2016.

[2] H. Liu and S. Li., "Speed control for PMSM servo system using predictive functional control and extended state observer," IEEE Trans Ind Electron, vol. 59(2), pp. 1171-1183, 2012.

[3] B. Alecsa, et al., "Simulink modeling and design of an efficient hardware-constrained FPGA-based PMSM speed controller," IEEE Trans IndInformat, vol. 8(3), pp. 544-562, 2012.

[4] D. Jiang, et al., "A sliding mode observer for PMSM speed and rotor position considering saliency," in Power Electronics Specialists Conference, PESC 2008.IEEE, pp. 809-814, 2008. 
[5] C. Jianbo, et al., "An improved sliding mode observer for position sensorless vector control drive of PMSM," in Power Electronics and Motion Control Conference, IEEE 6th International, pp. 1898-1902, 2009.

[6] M.Horch, A.Boumediene, L.Baghli, "MRAS-based Sensorless Speed Integral Backstepping Control for Induction Machine, using a Flux Backstepping Observer,"International Journal of Power Electronics and Drive System (IJPEDS), vol. 8, no. 4, pp. 1650-1662, 2017.

[7] C. Schauder, "Model Reference Adaptive System with Simple Sensorless Flux Observer for Induction Motor Drive," IEEE International Conference on Power Electronics, Drives and Energy Systems, pp.1-6, December16-19, 2012, Bengaluru, India.

[8] Bao DY, Wang H, Wang XJ, Zhang CR, "Sensorless speed control based on the improved Q-MRAS method for induction motor drives," Energies, 11:235, 2018.

[9] Zorgani YA, Koubaa Y, Boussak M., " MRAS state estimator for speed sensorless ISFOC induction motor drives with Luenberger load torque estimation," ISA Trans, 61:308-17, 2016.

[10] Suman. M, Chandan. C, Sabtasachi. S, "Simulation studies on model reference adaptive controller based speed estimation technique for the vector controlled permanent magnet synchronous motor drive," ELSEVIER, vol. 17, 2009.

[11] Z. Xingming, et al., "Wide-Speed-Range Sensorless Control of Interior PMSM Based on MRAS," International Conference, Electrical Machines and Systems (ICEMS), pp. 804-808, 2010.

[12] Larbi. M, Gherabi .Z, Doudar .K, "A Robust sensorless control of PMSM based on sliding mode observer and model reference adaptive system," International Journal of Power Electronics and Drive System (IJPEDS), vol. 8, no. 3, pp. 1016-1025, 2017.

[13] D. Solanki and P. R Sharma, "Sensorless Speed Control of PMSM Using MRAS Method," in 3rd International Conference on Role of Engineers as Entrepreneurs in Current Scenario, 2014.

[14] M. Larbi, S. Hassaine, S. Moreau, B. Mazari, "A robust fuzzy supervisor controller applied to a permanent magnet synchronous motor," IREE, vol. 6, n0.5, 2011.

[15] M. Irfan, Machmud Effendy, Nur Alif, Lailis S, Ilham Pakaya, Amrul Faruq, "Performance comparison of fuzzy logic and proportional-integral for an electronic load controller," International Journal of Power Electronics and Drive System (IJPEDS), vol. 8, no. 3, pp. 1176-1183, 2017.

Int J Pow Elec \& Dri Syst Vol. 10, No. 4, Dec 2019 : 1772 - 1780 